\title{
DEPOSIÇÕES METÁLICAS DO BRONZE FINAL NO VALE DO ASSUREIRA. O CASO DO SÍTIO DE MOINHOS DE GOLAS (SOLVEIRA, MONTALEGRE, NORTE DE PORTUGAL)
}

\author{
JOÃO FONTE ${ }^{(1)}$, ANA M. S. BETTENCOURT $^{(2)} \&$ ELIN FIGUEIREDO $^{(3)}$
}

Resumo:

Este trabalho tem como objetivo dar a conhecer um conjunto de achados metálicos do Bronze Final, em associação com fragmentos cerâmicos e líticos, encontrados no sítio de Moinhos de Golas, freguesia de Solveira, concelho de Montalegre.

A coleção metálica é composta por armas, artefactos de adorno, utensílios, possíveis elementos de produção metalúrgica, entre outros objetos de difícil classificação. As análises de composição química a peças selecionadas, embora preliminares, mostram que a maioria dos artefactos foram produzidos numa liga de bronze binário (Cu-Sn).

Pelo facto de terem sido encontradas dispersas por vários lugares do outeiro, este grupo de peças não pode considerar-se um depósito fechado.

Palavras-chave: Norte de Portugal, Bronze Final, deposições metálicas, bronze.

\begin{abstract}
Late Bronze Age metallic depositions in the AssureiraValley. The case study of Moinhos de Golas site (Solveira, Montalegre, Northern Portugal)

This work aims to publish a set of metal findings attributed to Bronze Age, and found in association with ceramic and lithic fragments. These were found in the Moinhos de Golas site, Solveira parish, in the Montalegre council.

This set consists of metallic weapons, ornaments, tools, and some objects that might be related to metallurgical processes, among other objects difficult to classify. Preliminary elemental analysis made on selected artefacts point out that most objects were produced in a binary bronze alloy.

This set of artefacts, given their finding circumstances, should not be regarded as a closed hoard.
\end{abstract}

Keywords: Northern Portugal, Late Bronze Age, metallic depositions, bronze.

Received: 6 August 2013; Accepted: 24 September 2013

\section{INTRODUÇÃO}

A importância arqueológica do sítio de Moinhos de Golas data de 2013, altura em que um dos signatários (JF) teve conhecimento de objetos metálicos e cerâmicos descobertos no local por Joe Horst, em 2003.

Segundo informações prestadas, os achados ocorreram à superfície, talvez resultantes da extração manual de pedra que ali terá ocorrido.

Em visita ao local foi ainda possível recolher alguns materiais metálicos e diversos fragmentos cerâmicos que, após devidamente estudados, foram depositados no Museu Regional de Arqueologia D. Diogo de Sousa, em Braga. Dada a importância e originalidade do acervo metálico e do seu contexto de achado, considerouse pertinente dá-lo a conhecer à comunidade científica, ainda que de forma preliminar.

\section{LOCALIZAÇÃO ADMINISTRATIVA E CONDICCÕES FÍSICAS E AMBIENTAIS}

O sítio localiza-se na freguesia de Solveira, concelho de Montalegre, distrito de Vila Real, nas seguintes coordenadas geográficas (datum WGS84): latitude $41.834468^{\circ}$; longitude $7.653446^{\circ}$ (graus decimais), à altitude máxima de 843 metros (Fig. 1).

\footnotetext{
${ }^{(1)}$ Instituto de Ciencias del Patrimonio (Incipit), Consejo Superior de Investigaciones Cientificas (CSIC), Santiago de Compostela, Espanha. E-mail: joao.fonte@incipit.csic.es

${ }^{(2)}$ Departamento de História da Universidade do Minho. Campus de Gualtar, 4710- 057 Braga, Portugal. Investigadora do Centro de Investigação Transdisciplinar, Cultura, Espaço e Memória - CITCEM / UM. E-mail: anabett@uaum.uminho.pt

(3) IST/ITN Campus Tecnológico e Nuclear, Instituto Superior Técnico, Universidade Técnica de Lisboa, Estrada Nacional 10, 2686-953 Sacavém, Portugal. Email: elin@ctn.ist.utl.pt. CENIMAT/I3N, Departamento de Ciências dos Materiais, Faculdade de Ciências e Tecnologia, Universidade Nova de Lisboa, 2829516 Caparica, Portugal.
} 

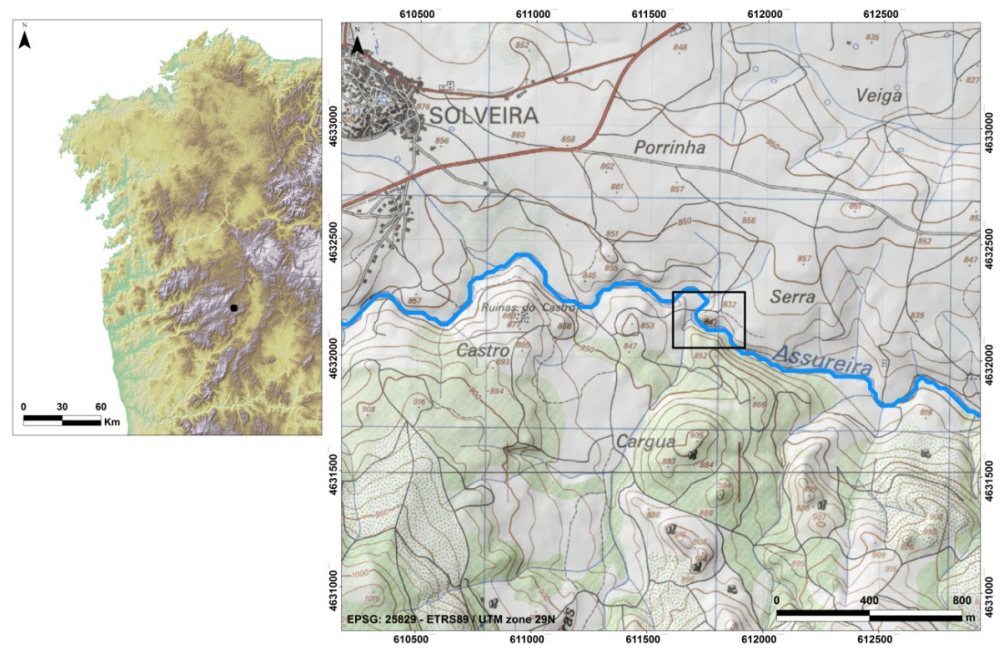

Fig. 1. Localização de Moinhos de Golas no Noroeste da Península Ibérica e na Carta Militar de Portugal n ${ }^{\circ}$ 20, à esc. 1: 25.000.

Fig.1. Location of Moinhos de Golas in the Northwest of Iberian Peninsula and in the Military Map of Portugal on the scale of 1:25.000.

O sítio de Moinhos de Golas corresponde a um outeiro sobranceiro à margem esquerda do rio Assureira, que o delimita a sul e a oeste, numa área de meandros acentuados e a cerca de 200/300 m para sudoeste do lugar de passagem fluvial de Pena Longa. Este rio é tributário do de Porto de Rei/ Búbal $^{4}$, afluente da margem direita do Tâmega, fazendo assim parte deste vale e, por consequência, da bacia do Douro.

Aqui aflora abundantemente o granito alcalino, de grão médio a grosseiro, de duas micas (TEIXEIRA \& ASSUNÇÃO 1970) que, pelas suas dimensões e formas, conferem ao local grande monumentalidade e permitem que se destaque no horizonte, apesar de se encontrar numa área depressionária do vale do Assureira (Fig. 2).

Segundo a notícia explicativa da Carta Geológica de Portugal $\mathrm{n}^{\circ} 2 \mathrm{D}$, a área é rica em recursos de estanho e de volfrâmio que se encontram associados a filões pegmatíticos e quartzosos respetivamente, estando assinaladas áreas de extração de volfrâmio em Lamago (Vilar de Perdizes) e no Alto dos Areais (Soutelinho da Raia), ambas a jusante dos Moinhos de Golas (TEIXEIRA \& ASSUNÇÃO 1970). Além desta informação, estudos arqueológicos têm revelado mineração abundante atribuída à época Romana, nas áreas das freguesias de Solveira e de Gralhas, a montante dos Moinhos de Golas (CARVALHO et al. 2006). Informações orais colhidas em Solveira, por uma das signatárias deste trabalho (AMSB), permitiram precisar que, no lugar de Farturas dessa freguesia, houve exploração de volfrâmio durante a Segunda Guerra Mundial (Fig. 3). Perante as características da geologia regional e os dados relativos à mineração antiga é de presumir que os aluviões do Assureira fossem ricas em minerais metálicos, nomeadamen- te em cassiterite, passíveis de fácil extração na antiguidade.

O local encontra-se coberto por vegetação arbustiva com algumas urzes brancas e giestas e vegetação herbácea. Pontualmente existem alguns carvalhos. Nas margens do Assureira existe uma floresta ribeirinha, bem preservada, composta essencialmente por Amieiros. Nas imediações os campos são usados para a agricultura.

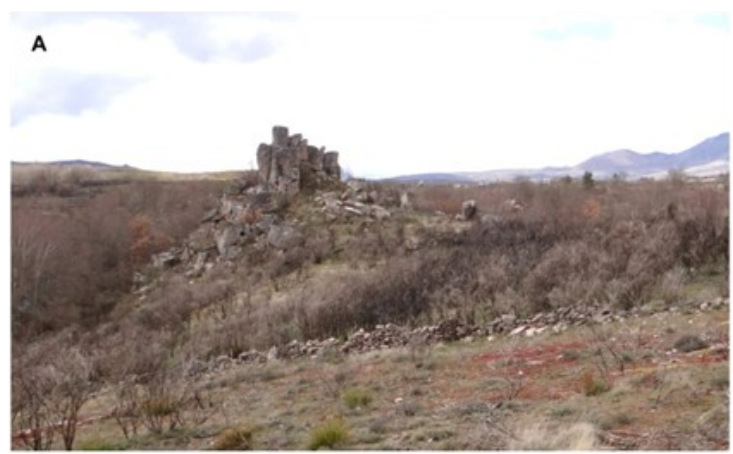

B

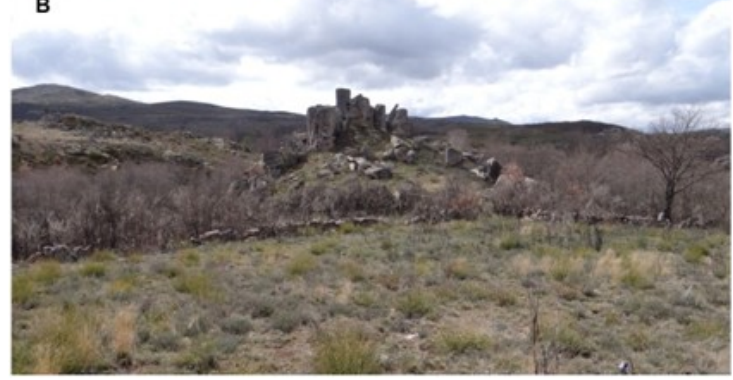

Fig. 2. Moinhos de Gola visto de nascente (A) e pelo lado nornordeste (B). A norte dos afloramentos dispostos na vertical, pode observar-se uma pequena plataforma.

Fig. 2. Moinhos de Gola from East (A); Moinhos de Gola observed by the north-northeast side (B). It can be noted a small platform to the north of the top outcrops. 


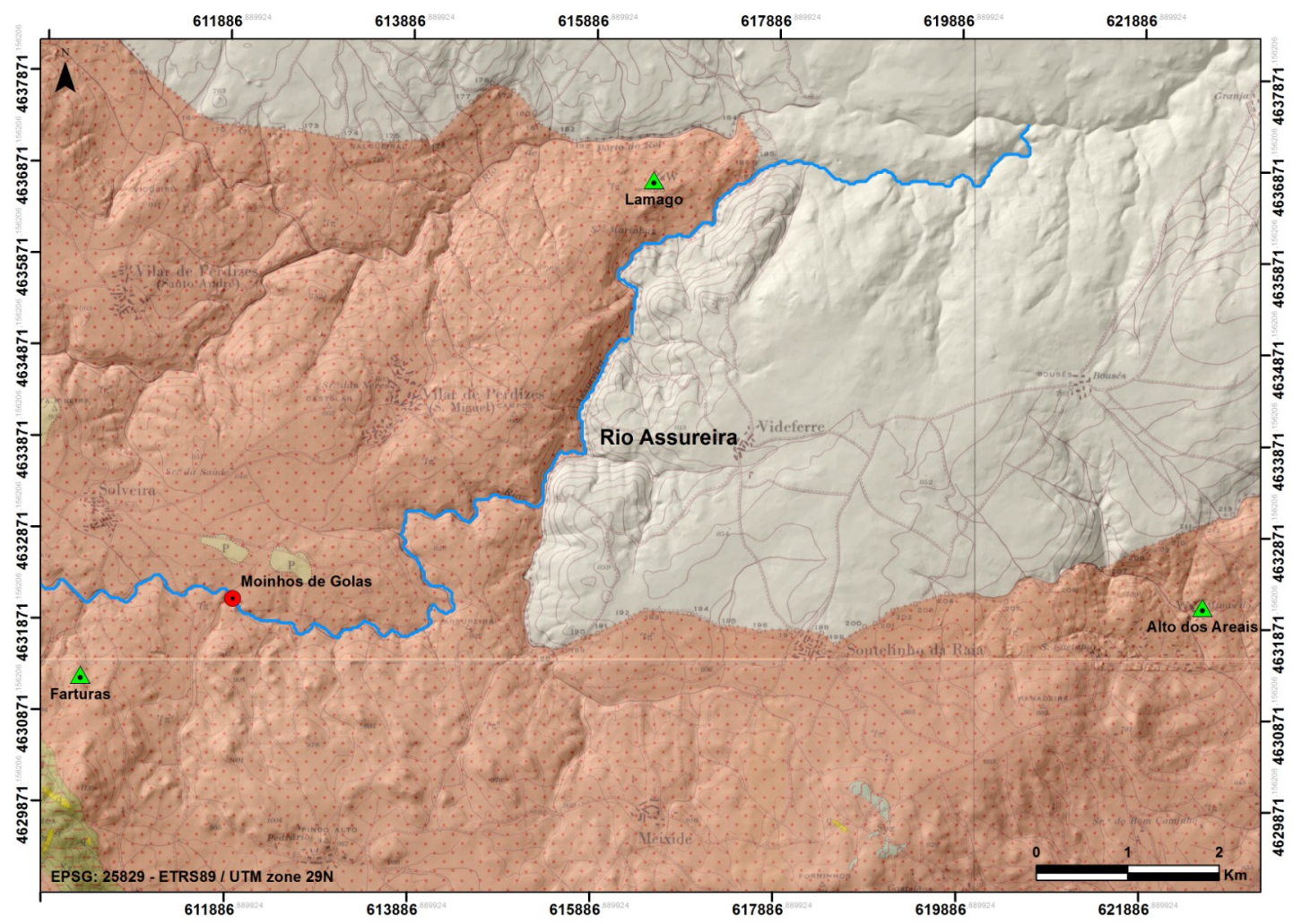

Fig. 3. Carta Geológica de Portugal de Vilar de Perdizes, $n^{\circ}$ 2D, com sinalização de algumas áreas de mineração de volfrâmio. Fig. 3. Geological Map of Portugal, Vilar de Pinheiros, No. 2D, with some areas of tungsten mining.

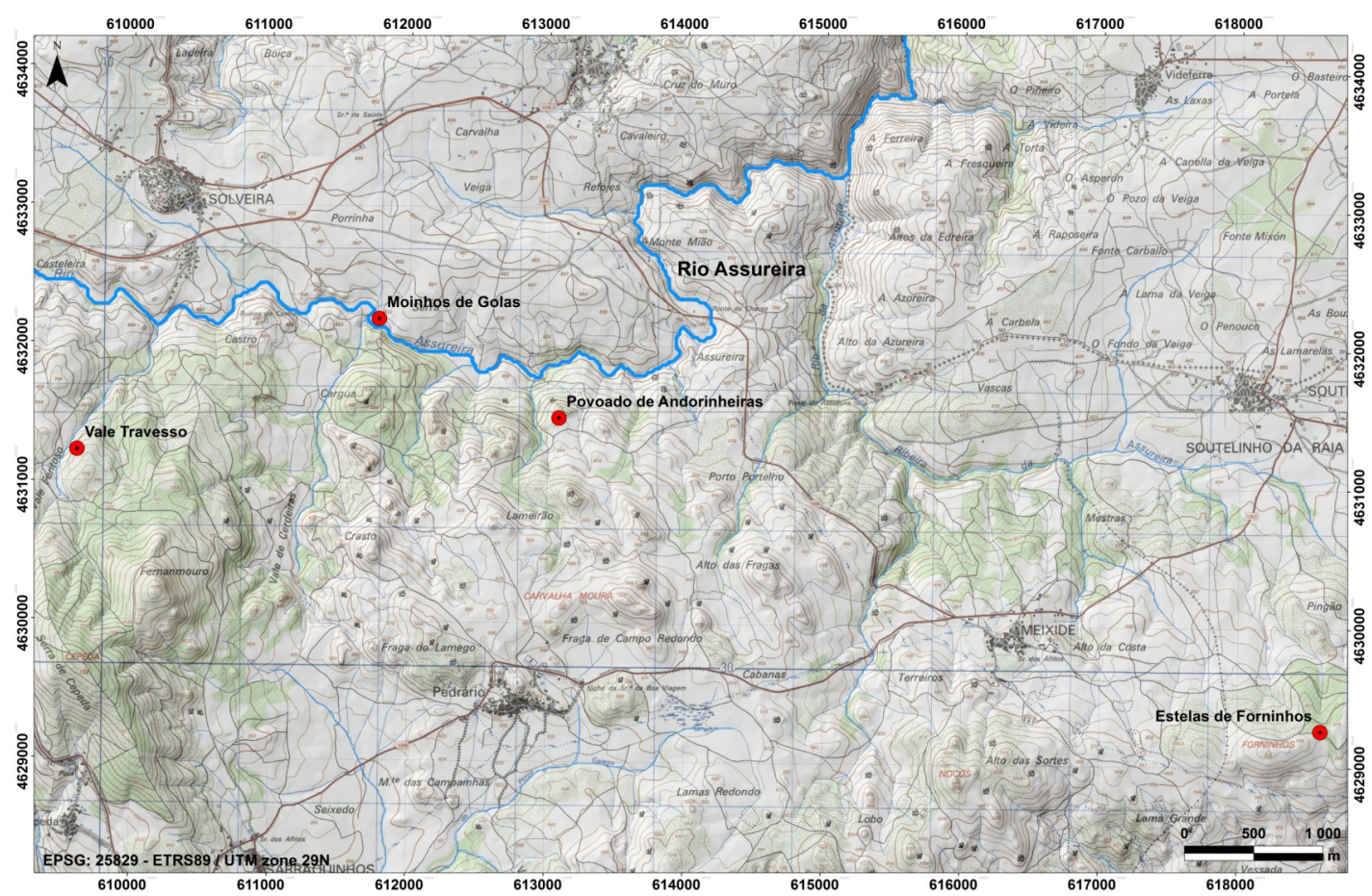

Fig. 4. Vestígios arqueológicas da Idade do Bronze no vale do Assureira.

Fig. 4. Bronze Age archaeological sites in the Assureira valley. 


\section{CONTEXTO ARQUEOLÓGICO}

O contexto arqueológico do sítio de Moinhos de Golas, em particular no que respeita ao vale do Assureira, caracteriza-se, na Idade do Bronze, por alguns achados relevantes. Desde logo, cabe destacar o depósito metálico de Vale Travesso em Solveira, encontrado acidentalmente em 1961 (COSTA 1963), nas imediações de um curso de água que desagua na margem direita do Assureira. É composto por quatro objetos em bronze: um machado de talão de dupla argola, duas pontas de lança e uma fúrcula ou garfo, classificado como votivo por Bettencourt (2006). De destacar, também, as duas estelas com iconografia típica do sudoeste da Ibéria, encontradas na vertente nordeste do Monte de Forninhos, lugar de Castelões, freguesia de Calvão, concelho de Chaves, nas imediações de um antigo caminho que ligava Montalegre a Chaves e que passava nas imediações dos Moinhos de Golas (BETTENCOURT 2013).

Ainda deste período genérico podemos considerar o povoado de Andorinheiras, inédito, a cerca de $1500 \mathrm{~m}$ para nascente de Moinhos de Golas, pertencente à freguesia de Vilar de Perdizes. Localiza-se na margem direita do Assureira, elevando-se a uma altitude de $874 \mathrm{~m}$. As cerâmicas encontradas à superfície parecem enquadrar-se, genericamente, dentro da Idade do Bronze, sem conseguirmos precisar, de momento, se este sítio poderá ser coetâneo de Moinhos de Golas, para o qual tem intervisibilidade direta.

\section{DESCRIÇÃO DOS ACHADOS METÁLICOS}

Por uma questão operativa, optámos por subdividir os achados em quatro grandes categorias: armas; utensílios; objetos de adorno; elementos de produção metalúrgica e outros. Nesta última categoria colocámos as peças de difícil classificação.

Os achados metálicos foram estudados em termos formais e em termos da sua composição química.

\subsection{Descrição formal}

Foram recolhidos, até à data, trinta e cinco artefactos, que passamos a descrever.

\section{$\underline{\text { Armas }}$}

Neste grupo incluímos três punhais de diversas formas e dimensões (Fig. 5).

\section{Punhal no1 (MDDS 2013.0423)}

Trata-se de um punhal inteiro, de lâmina tendencialmente triangular com nervura longitudinal. A lingueta, não individualizada, de forma arredondada, apresenta um orifício. Mede 12,6 cm de comprimento, $2,2 \mathrm{~cm}$ de largura máxima e $0,5 \mathrm{~cm}$ de espessura. Pesa 24,2 gramas. Encontra-se em estado de corrosão ativa (Fig. 5a).

\section{Punhal $n^{\circ} 2$ (MDDS 2013.0424)}

Trata-se de um punhal parcialmente fragmentado na lingueta, de lâmina tendencialmente triangular. A lingueta, não individualizada, apresenta ainda indícios de dois orifícios dispostos horizontalmente. Mede 11,9 cm de comprimento, $1,5 \mathrm{~cm}$ de largura máxima e $0,3 \mathrm{~cm}$ de espessura. Pesa 14,7 gramas (Fig. 5b).

\section{Punhal no 3 (MDDS 2013.0425)}

Trata-se de um fragmento de um punhal que conserva, ainda, parte de uma lâmina plana e de uma lingueta. Esta apresenta um orifício onde se pode observar um rebite. Mede 4,5 $\mathrm{cm}$ de comprimento, $1,3 \mathrm{~cm}$ de largura máxima e $0,2 \mathrm{~cm}$ de espessura. Pesa 4,2 gramas (Fig. 5c).

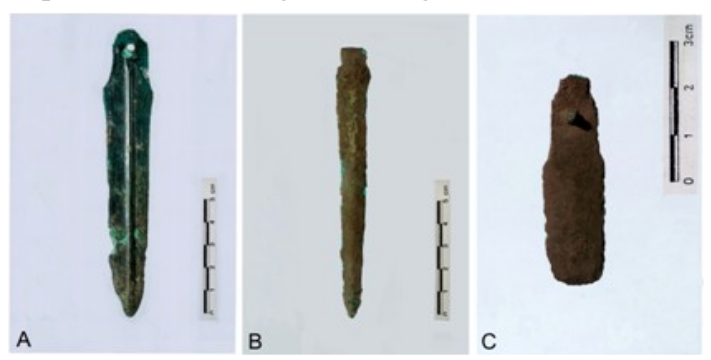

Fig. 5. Punhais de tipo Porto de Mós. Fig. 5. Daggers of Porto de Mós type.

\section{Utensílios}

Inserimos nesta categoria o que consideramos um tranchet, um eventual freio e dois eventuais passadouros de correias (Fig. 6).

\section{Tranchet (MDDS 2013.0426)}

Trata-se de um tranchet com área de encabamento em forma de lingueta, cuja separação com a lâmina se faz através de uma nervura horizontal, existente apenas num dos lados. Esta peça pode ser classificada como um tranchet unifacial de lingueta de espigão, de tipo Atlântico, relativamente raro na Península Ibérica (cf. VILAÇA 2008-2009). O gume, desgastado pela erosão, é ligeiramente arredondado. Mede 6,5 cm de comprimento, $3,2 \mathrm{~cm}$ de largura no gume, $0,1 \mathrm{~cm}$ de largura mínima, na lingueta, $0,3 \mathrm{~cm}$ de espessura da lâmina, $0,45 \mathrm{~cm}$ de espessura da lingueta e 0,5 de espessura na área da nervura. Pesa 20,1 gramas (Fig. 6a e Fig. 11).

Aro rematado por duas argolas/Freio (?)
(MDDS 2013.0428)
Trata-se de um aro comprido e dobrado nas
extremidades para a contenção de uma argola de
cada lado; num dos lados a argola encontra-se ain-
da encaixada. A função desta peça é discutível,
podendo-se propor uma possível pega de recipiente
ou um possível freio de cavalo, apesar da sua rela-

\footnotetext{
${ }^{5}$ Número de inventário do Museu Regional de Arqueologia D. Diogo de Sousa em Braga, local onde o material se encontra depositado.
} 
tiva finura. $\mathrm{O}$ aro é de seção circular, com $0,25 \mathrm{~cm}$ de diâmetro, e no estado de deformação atual tem $10,7 \mathrm{~cm}$ de largura e $10,5 \mathrm{~cm}$ de altura. Ambas as argolas têm seção subcircular, com $3,4 \mathrm{~cm}$ de diâmetro, tendo uma $0,3 \mathrm{~cm}$ e a outra $0,2 \mathrm{~cm}$ de espessura. Pesa 13,9 gramas (Fig. 6b).

\section{Vareta/Passador de correia 1 (?) (MDDS 2013.0450)}

Pequena haste de seção cilíndrica com ligeiro espessamento em ambas as extremidades. Tem 1,9 $\mathrm{cm}$ de comprimento máximo, $0,55 \mathrm{~cm}$ de espessura central e $0,7 \mathrm{~cm}$ de espessura em ambas as extremidades. Em alternativa, pode-se propor um possível passador de correia, sendo que o desgaste da parte central está provavelmente relacionado com o uso intenso da peça. Pesa 3 gramas (Fig. 6c).

\subsection{1) \\ Vareta/Passador de correia 2 (?) (MDDS}

Haste de seção cilíndrica com ligeiro espessamento em ambas as extremidades, embora uma delas esteja parcialmente partida. Tem $2,2 \mathrm{~cm}$ de comprimento máximo, $0,95 \mathrm{~cm}$ de espessura central e $1,1 \mathrm{~cm}$ de espessura na extremidade melhor conservada. A interpretação desta peça é semelhante à anteriormente exposta. Pesa 10,2 gramas (Fig. 6d).

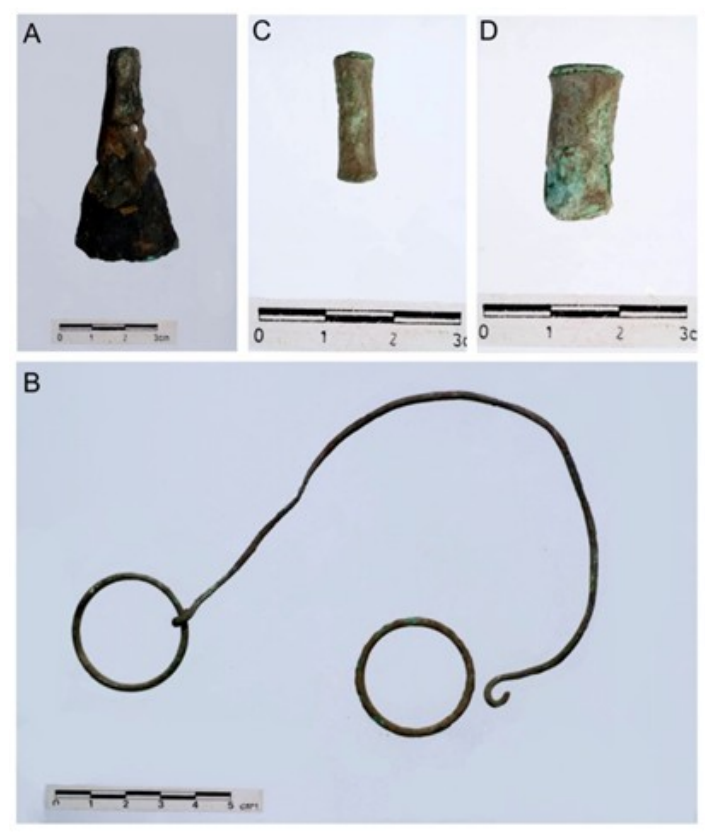

Fig. 6. Tranchet (a); Aro rematado por argolas/Freio (?)(b); Vareta/Passador de correia 1 (?) (c); Rebite/Passador de correia 2 (?) (d).

Fig. 6. Tranchet (a); Rim with one ring at each end/Brake horse (?)(b); Rod/dowel belt 1(?) (c); Rod/dowel belt 1(?) (d).

\section{Objetos de adorno}

Incluímos neste grupo um botão e dois alfinetes (Fig. 7).

\section{Botão (MDDS 2013.0446)}

Botão de cabeça arredondada com ligeira aba, de contorno tendencialmente oval. Entre a aba e a superfície arredondada existe uma decoração composta por pequenos traços, paralelos entre si. $\mathrm{Na}$ face inferior contêm um mecanismo de fixação no interior da cabeça do botão, de forma subcircular. Mede 1,9 cm de diâmetro, 1,65 cm de largura, $0,7 \mathrm{~cm}$ de altura e $0,15 \mathrm{~cm}$ de espessura da aba. Pesa 3,4 gramas (Figs. 7a(1), 7a(2) e Fig. 11).

\section{Alfinete/Pendente 1 (?)(MDDS 2013.0448)}

Possível alfinete de cabeça de forma ovalada com a extremidade superior aguçada. Tendo em consideração o seu peso, também poderá ser um possível pendente. A cabeça tem 1,3 cm de largura e 1,5 de altura. O pé, parcialmente fragmentado, de seção circular, tem $0,3 \mathrm{~cm}$ de espessura máxima. A altura conservada é de $3,5 \mathrm{~cm}$. Pesa 10,6 gramas (Fig.7b).

\section{Alfinete/Pendente 2 (?)(MDDS 2013.0449)}

Possível cabeça de alfinete de forma ovalada com a extremidade superior aguçada. Tendo em consideração o seu peso, também poderá ser

um possível pendente. A cabeça tem $1,1 \mathrm{~cm}$ de largura e 1,4 de altura. $O$ que resta do pé de seção circular tem $0,3 \mathrm{~cm}$ de espessura máxima. A altura conservada é de $2 \mathrm{~cm}$. Pesa 5,8 gramas (Fig. $7 \mathrm{c})$.
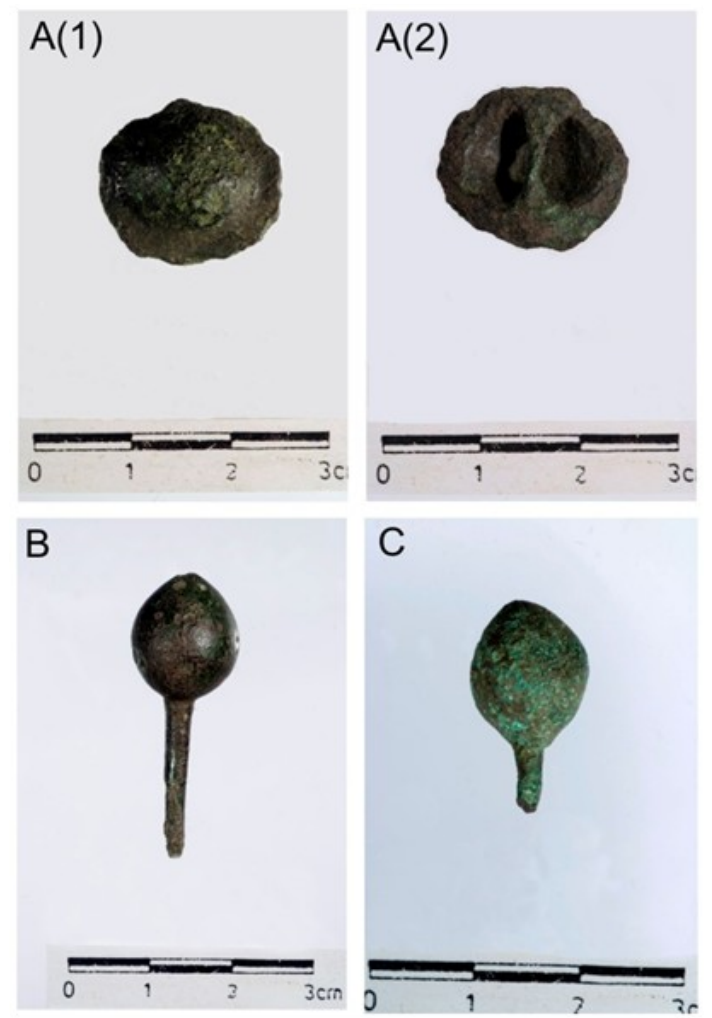

Fig. 7. Botão (a); Alfinete/Pendente 1 (?)(b); Alfinete/ Pendente 2 (?) (c).

Fig. 7. Button (a); Hair pin/Pendant 1 (?) (b); Hair pin/Pendant 2 (?) (c). 
Elemento relacionado com a produção metalúrgica

Nesta categoria apenas inserimos o que classificámos como um lingote.

\section{Lingote (?) (MDDS 2013.0427)}

Trata-se de um possível lingote paralelepípedo, de seção quadrangular. Mede 2,7 cm de comprimento, $1,1 \mathrm{~cm}$ de largura máxima e 0,9 de espessura. Pesa 18,9 gramas (Fig.8).

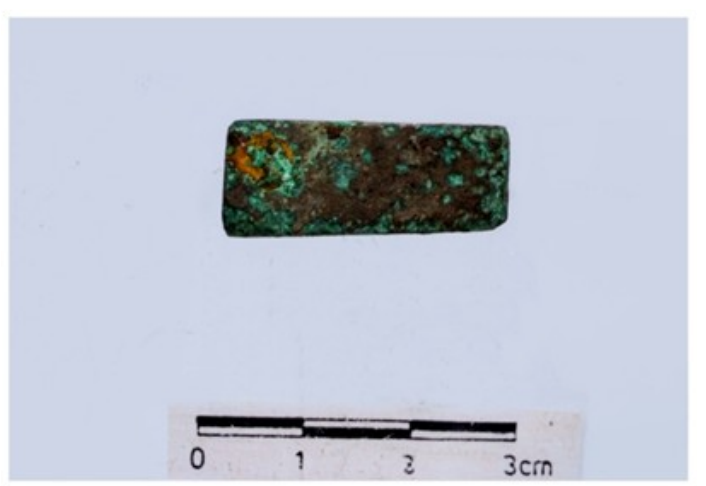

Fig. 8. Lingote (?).

Fig. 8. Ingot (?).

\section{Outros}

Neste grupo incluímos a maioria das argolas, um cravo, um artefacto em forma de cápsula e o que designámos por varetas ou hastes, de difícil interpretação (Figs. 9, 10 e 11).

\section{Vareta 1 (MDDS 2013.0452)}

Fragmento de vareta ligeiramente arqueada, de seção quadrangular. Tem $9,1 \mathrm{~cm}$ de comprimento e $0,7 \mathrm{~cm}$ de espessura. Pesa 34,8 gramas (Fig. 9a).

\section{Vareta 2 (MDDS 2013.0453)}

Vareta arqueada, de seção circular, adelgaçada e pontiaguda numa das extremidades e partida na outra. Tem 12,4 cm de comprimento, $0,65 \mathrm{~cm}$ de espessura máxima e $0,15 \mathrm{~cm}$ de espessura mínima. Pesa 15,8 gramas (Fig. 9b).

\section{Vareta 3 (MDDS 2013.0454)}

Fragmento de vareta arqueada, de seção circular, estreitando em ambas as extremidades que se encontram fragmentadas. Tem $16,4 \mathrm{~cm}$ de comprimento na posição original, $8,4 \mathrm{~cm}$ de largura, 0,55 $\mathrm{cm}$ de espessura máxima e $0,30 \mathrm{~cm}$ de espessura mínima. Pesa 26,4 gramas (Fig. 9c).

\section{Vareta 4 (MDDS 2013.0455)}

Fragmento de vareta ligeiramente arqueada, de seção trapezoidal. Apresenta alguns vácuos à superfície. Tem $3,8 \mathrm{~cm}$ de comprimento e $0,6 \mathrm{~cm}$ de espessura. Pesa 5,7 gramas (Fig. 9d).

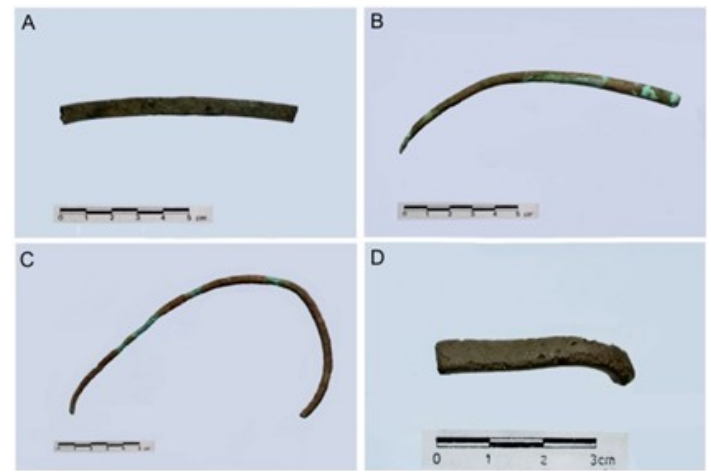

Fig. 9. Fragmentos de varetas de diferentes peças. Fig. 9. Rods fragments of different artefacts.

\section{Placa fragmentada (MDDS 2013.0456)}

Placa sensivelmente retangular que se encontra dobrada, em parte. Está parcialmente partida numa das extremidades. No anverso, apresenta evidências de ter servido de cobertura a qualquer objeto efetuado em material perecível. Tem 2,35 $\mathrm{cm}$ de largura, 2,5 $\mathrm{cm}$ de comprimento atual e 0,05 $\mathrm{cm}$ de espessura. Pesa 1,6 gramas (Fig. 10a).

\section{Cravo (MDDS 2013.0447)}

Cravo de cabeça arredondada, de contorno semicircular, com $1.9 \mathrm{~cm}$ de diâmetro. O pé é de seção subretangular e mede $0,3 \mathrm{~cm}$ de espessura. Tem 2,3 cm de altura total. Pesa 3,7 gramas (Fig. 10b).

\subsection{7)}

Objeto em forma de cápsula (MDDS

Artefacto em forma de cápsula. Excluímos a hipótese de poder ser uma cabeça de cravo, apesar de não ter evidências do pé. Por outro lado, não seria de rejeitar a hipótese de corresponder a uma extremidade de ponteira de bainha ou a um elemento de adorno de punho de um punhal, tendo por base as interpretações efetuadas para uma peça similar (na forma e dimensões) proveniente da anta da Cunha Baixa em Mangualde (NUNES et al. 1989). A cápsula é tendencialmente globular com ligeira carena e contorno circular. Tem de largura 1 $\mathrm{cm}$ e $0,75 \mathrm{~cm}$ de altura. Pesa 1,1 gramas (Fig. 10c e Fig. 11).

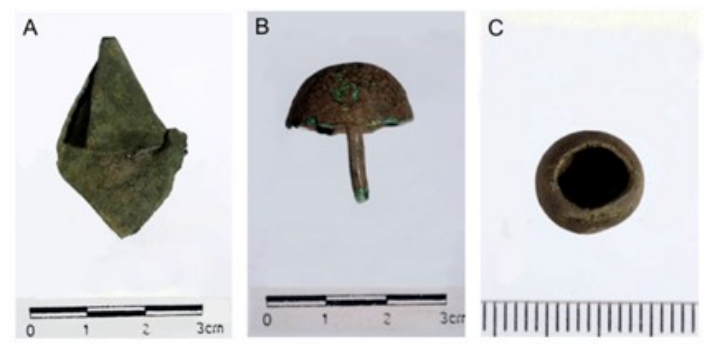

Fig. 10. Placa de cobre (a); Cravo (b); Objeto em forma de cápsula (c).

Fig. 10. Copper plate (a); Rivet (b); Object in capsule form (c). 


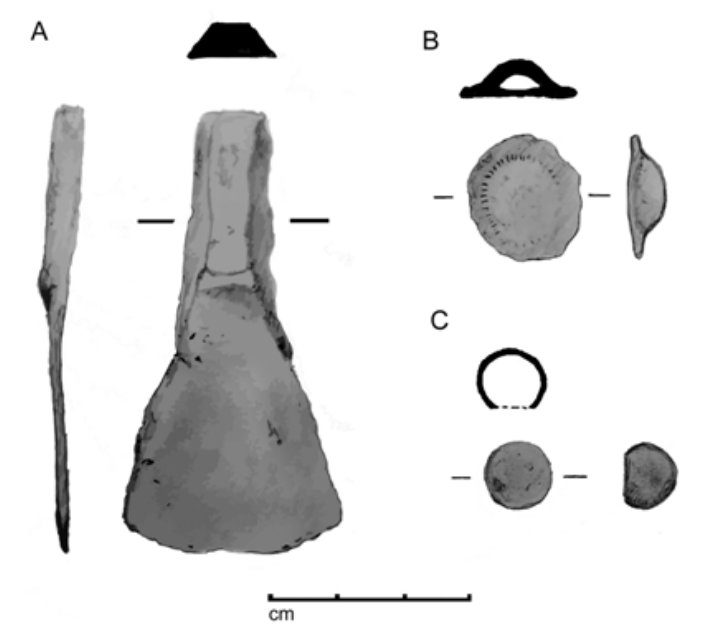

Fig. 11. Desenhos de Tranchet (MDDS 2013.0426) (a); Botão (MDDS 2013.0446) (b); Objeto em forma de cápsula (MDDS 2013.0457) (c).

Fig. 11. Drawings of Tranchet (MDDS 2013.0426) (a); Button (MDDS 2013.0446) (b); Object in capsule form (MDDS 2013.0457) (c).

\section{Argola 1 (MDDS 2013.0429)}

Argola com 3,8 cm de diâmetro. Tem um aro de seção circular com $0,3 \mathrm{~cm}$ de espessura. Pesa 3,5 gramas (Fig. 11a).

\section{Argola 2 (MDDS 2013.0430)}

Argola com 3,2 cm de diâmetro. Tem um aro de seção circular com $0,2 \mathrm{~cm}$ de espessura. Pesa 1,8 gramas (Fig. 11b).

\section{Argola 3 (MDDS 2013.0431)}

Argola com 3,2 cm de diâmetro. Tem um aro de seção circular com $0,2 \mathrm{~cm}$ de espessura. Pesa 1,6 gramas. $\mathrm{O}$ estado de corrosão é avançado (Fig. 11c).

\section{Argola 4 (MDDS 2013.0432)}

Argola com 3,2 cm de diâmetro. Tem um aro de seção circular com $0,2 \mathrm{~cm}$ de espessura. Pesa 1,4 gramas. $\mathrm{O}$ estado de corrosão é avançado (Fig. 11d).

\section{Argola 5 (MDDS 2013.0433)}

Argola com 3,2 cm de diâmetro. Tem um aro de seção circular com $0,2 \mathrm{~cm}$ de espessura. Pesa 1,6 gramas. O estado de corrosão é avançado (Fig. 11e).

\section{Argola 6 (MDDS 2013.0434)}

Argola com 2,45 cm de diâmetro. Tem um aro de seção circular com $0,3 \mathrm{~cm}$ de espessura. Pesa 1,7 gramas (Fig. 11f).

\section{Argola 7 (MDDS 2013.0435)}

Argola com 2,4 cm de diâmetro. Tem um aro de seção circular com $0,35 \mathrm{~cm}$ de espessura. Pesa 2,4 gramas (Fig. 11g).

\section{Argola 8 (MDDS 2013.0436)}

Argola com 2,4 cm de diâmetro. Tem um aro de seção circular com $0,25 \mathrm{~cm}$ de espessura. Pesa

\section{2,6 gramas (Fig. 11h).}

\section{Argola 9 (MDDS 2013.0437)}

Argola com 2,65 cm de diâmetro. Tem um aro de seção circular com $0,35 \mathrm{~cm}$ de espessura. Pesa 2,5 gramas. Em duas extremidades opostas do aro apresenta desgaste interno. Estado de corrosão avançado (Fig. 11i).

\section{Argola 10 (MDDS 2013.0438)}

Argola com 2,3 cm de diâmetro. Tem um aro de seção subretangular com $0,4 \mathrm{~cm}$ de espessura. Pesa 3,6 gramas (Fig. 11j).

\section{Argola 11 (MDDS 2013.0439)}

Argola com 2,4 cm de diâmetro. Tem um aro de seção grosseiramente circular com $0,35 \mathrm{~cm}$ de espessura. Pesa 3,5 gramas (Fig. 111).

\section{Argola 12 (MDDS 2013.0440)}

Argola com 2,2 cm de diâmetro. Tem um aro de seção circular com $0,3 \mathrm{~cm}$ de espessura. Pesa 1,9 gramas (Fig. $11 \mathrm{~m}$ ).

\section{Argola 13 (MDDS 2013.0441)}

Argola com $2 \mathrm{~cm}$ de diâmetro. Tem um aro de seção semicircular com $0,3 \mathrm{~cm}$ de espessura. Pesa 1,4 gramas (Fig. 11n).

\section{Argola 14 (MDDS 2013.0442)}

Argola com 2,1 cm de diâmetro. Tem um aro de seção circular com $0,35 \mathrm{~cm}$ de espessura. Pesa 3,2 gramas (Fig. 11o).

\section{Argola 15 (MDDS 2013.0443)}

Argola com 1,81 cm de diâmetro. Tem um aro de seção circular com $0,5 \mathrm{~cm}$ de espessura. Pesa 3,6 gramas (Fig. 11p).

\section{Argola 16 (MDDS 2013.0444)}

Argola com 2,2 cm de diâmetro, $0,5 \mathrm{~cm}$ de espessura. Apresenta seção e aro interior irregular devido ao facto de conter, num dos lados, rebarbas de fundição. Pesa 3,6 gramas (Fig. 11q).

\section{Argola 17 (MDDS 2013.0445)}

Argola com 1,8 cm de diâmetro, $0,5 \mathrm{~cm}$ de espessura, seção e aro interior irregular devido ao facto de apresentar, num dos lados, rebarbas de fundição. Pesa 1,4 gramas (Fig. 11r).

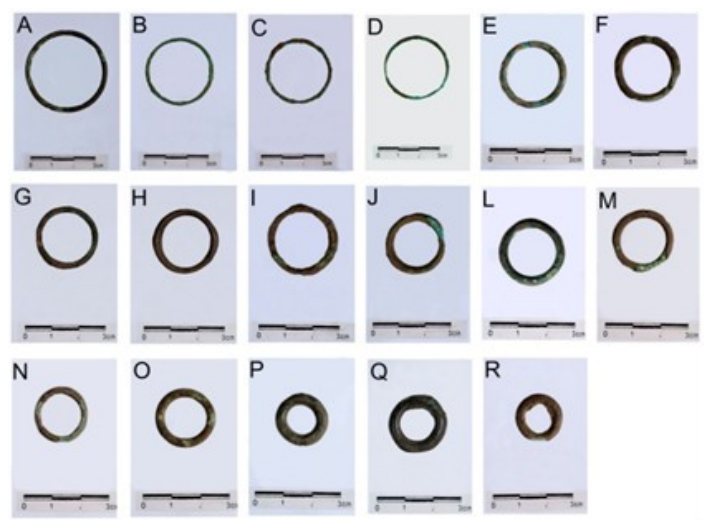

Fig. 12. Argolas.

Fig. 12. Rings. 


\subsection{Composição química}

Foram efetuadas análises elementares com um espectrómetro de fluorescência de raios X (FRX) portátil $^{6}$ em treze artefactos selecionados ${ }^{7}$, com o objetivo de caraterizarmos, ainda que genericamente, o tipo de metal ou de ligas metálicas utilizadas no fabrico das peças. De registar que não foi realizada uma calibração específica para o presente estudo, tendo sido usada a calibração interna do equipamento.

Os resultados consideram-se como semiquantitativos uma vez que as análises foram efetuadas sem preparação prévia das superfícies dos artefactos estando, assim, afetados pela composição da camada de corrosão. No entanto, apesar de semiquantitativos, poderão servir para diferenciar objetos de cobre dos de bronze e, eventualmente, diferenciar bronzes binários $(\mathrm{Cu}-\mathrm{Sn})$ de bronzes ternários $(\mathrm{Cu}-\mathrm{Sn}-\mathrm{Pb})$.

Devido à corrosão dos bronzes arqueológicos os resultados das análises superficiais sofrem, geralmente, um desvio relativamente ao da liga inalterada. Como resultado, o estanho e o chumbo estão frequentemente enriquecidos à superfície em relação ao cobre, que sofre uma lixiviação preferencial durante o enterramento (RoBBIOLA et al. 1998). De uma forma geral, e tendo como base estudos prévios em bronzes arqueológicos por FRX (FIGUEIREDO et al. 2007a, 2007b), podem esperar-se aumentos no valor do estanho e do chumbo até $5 \times$, quando comparadas com o seu teor na liga inalterada. É, também, comum a presença de ferro na corrosão devido à incorporação deste elemento a partir das terras de enterramento.

Apesar destes constrangimentos os resultados das análises efetuadas aos artefactos selecionados de Moinhos de Golas mostraram que todos, exceto um, além do elemento maioritário cobre, continham a presença de estanho e, nalguns deles, a presença de chumbo e de ferro (Quadro 1). Tendo em conta o enriquecimento superficial esperado para os elementos de estanho e de chumbo, relativamente ao cobre, nas camadas de corrosão, e a incorporação de ferro das camadas de corrosão devido a contaminação dos solos de enterramento, pode considerar-se, embora de forma provisória, que a maioria dos objetos foram fabricados numa liga de bronze binária, com baixos e/ou variáveis teores de chumbo, sendo que o fragmento de placa se destaca, por não ter sido detetado o elemento estanho, permitindo, assim, classificá-lo como sendo de cobre.

Quadro 1 / Table 1

\begin{tabular}{|c|c|c|c|c|c|c|}
\hline & $\begin{array}{l}\mathrm{N}^{0} \text {. Inventário } \\
\text { (MDDS) }\end{array}$ & $\mathrm{Cu}$ & Sn & $\mathbf{P b}$ & $\mathrm{Fe}^{*}$ & Tipo de liga** \\
\hline Vareta 3 & 2013.0454 & +++ & + & + & + & Bronze binário(?) \\
\hline Punhal 1 tipo Porto de Mós & 2013.0423 & +++ & ++ & vest. & vest. & Bronze binário \\
\hline Tranchet (?) atípico & 2013.0426 & ++ & ++ & n.d. & vest. & Bronze binário \\
\hline Lingote (?) & 2013.0427 & +++ & ++ & vest. & vest. & Bronze binário \\
\hline Alfinete 1 & 2013.0448 & ++ & +++ & vest. & + & Bronze binário \\
\hline Cravo & 2013.0447 & +++ & ++ & vest. & + & Bronze binário \\
\hline Haste 2 & 2013.0451 & +++ & ++ & vest. & + & Bronze binário \\
\hline Argola & 2013.0444 & +++ & ++ & + & + & Bronze binário(?) \\
\hline Punhal 3 & 2013.0425 & +++ & ++ & vest. & + & Bronze binário \\
\hline Placa fragmentada & 2013.0456 & +++ & n.d. & n.d. & vest. & Cobre \\
\hline Botão & 2013.0446 & +++ & ++ & vest. & vest. & Bronze binário \\
\hline Vareta 1 & 2013.0452 & +++ & + & n.d. & vest. & Bronze binário \\
\hline Punhal 2 & 2013.0424 & +++ & ++ & + & vest. & Bronze binário(?) \\
\hline
\end{tabular}

$+++>50 \%$; ++ 10-50\%; + 1-10\%; vest. (Vestígios) $<1 \%$; n.d. não detetado.

* O ferro aparece comummente nas camadas de corrosão, podendo estar ausente na liga metálica original.

** Interpretação baseada na análise de superfície (com influência das camadas de corrosão), carecendo de um estudo arqueometalúrgico mais detalhado.

* The iron is frequently present in corrosion layers despite it can be absent in the unaltered metal

** Interpretation based on the present superficial analysis (with influence from the corrosion layers). A detailed archaeometallurgical study can give further details.

${ }^{6}$ Espectrómetro Thermo Scientific Niton XL3t XRF Analyser (http://www.niton.com/en/niton-analyzers-products/xl3/xl3t).

${ }^{7}$ A dimensão e geometria de algumas tipologias, como os anéis, com superfícies curvilíneas e muito estreitas, dificultou a análise preliminar nestes artefactos. 


\section{DISCUSSÃO DOS RESULTADOS E INTERPRE- TAÇÕES}

Pelas suas características formais e pelos resultados da análise de composição química, este conjunto de artefactos metálicos insere-se no Bronze Final $^{8}$. Pelo facto das peças metálicas não terem sido encontradas em associação, mas antes dispersas pelas diferentes plataformas dos Moinhos de Golas, consideramos que não se trata de um depósito fechado.

$\mathrm{O}$ grande número de objetos inteiros ou quase, em número de vinte e oito $90 \%$, a sua tipologia e o seu estado geral de conservação, também não permite colocar a hipótese de estarmos perante restos de sucata para refundição ou reciclagem. De notar que, mesmo as pequenas peças incompletas, como os alfinetes e, pelo menos, um dos punhais, têm fraturas recentes ou denotam estados de corrosão que se explicam por processos pósdeposicionais e pelas condições de achado. Talvez o mesmo se possa dizer para o punhal 3 e para a vareta 2 .

Deste modo, ao considerarmos que não se trata de um depósito fechado e estático, podemos, em alternativa, sugerir um possível caráter aberto do depósito, enquanto fenómeno dinâmico e complexo que resulta de um processo cumulativo de um ou mais atos sucessivos de deposição ao longo de um certo período de tempo (HARDING 2003: 323 ), o qual se pode traduzir em pequenos depósitos dispersos a formar verdadeiros "campos de depósitos" (VILAÇA 2006: 39).

A manufatura da maioria dos artefactos encontrados, numa liga de bronze binário com a eventual presença de chumbo como impureza, está de acordo com a generalidade do que se conhece sobre as produções metalúrgicas do Bronze Final para o território nacional (VILAÇA 1997; BETTENCOURT 1998; 2001; FIGUEIREDO 2010; FIGUEIREDO et al. 2011a; VILAÇA et al. 2011; BOTTAINI 2012). Referimo-nos, por exemplo, a vários sítios arqueológicos do Norte de Portugal, como S. Julião Ia/Ib, Santinha I, Lavra II, Coto da Pena IA, etc. (Bettencourt 2001), o depósito de Vale Travesso (BotTAINI 2012); a diversos do grupo Baiões/ Santa Luzia, na Beira Alta, como o Castro da Senhora da Guia de Baiões (VALÉRIO et al. 2006; FigUEIREDO et al. 2010a), o Castro de Santa Luzia (FigUeIREDO et al. 2006), Figueiredo das Donas (FIGUEIREDO et al. 2011b); o Crasto de São Romão (FIGUEIREDO et al. 2010b) e Canedotes (VALÉRIO et al. 2007). O mesmo ocorre para vários sítios arqueológicos na Beira Baixa (VILAÇA 1997; VILAÇA et al. 2011), assim como para várias coleções de artefatos metálicos provenientes da Estremadura, como é o caso do Castro de Pragança
(FIGUEIREDO et al. 2007c), da Gruta do Medronhal (FigueIREDo et al. 2013), do depósito da Freixianda (GUTIÉRREZ NeIRA et al. 2011) e do Depósito de Coles de Samuel (COFFYN 1985; BOtTAINI 2012).

Estes resultados parecem inserir, mais uma vez, o Norte de Portugal numa tradição metalúrgica mediterrânica, pelo menos em termos tecnológicos, tal como já se tem defendido anteriormente (VILAÇA 1997; BETTENCOURT 1998, 2001).

\section{AGRADECIMENTOS}

Este trabalho foi desenvolvido no âmbito dos projetos Metalurgia Primitiva no Território Português - EARLYMETAL (PTDC/HIST-ARQ/110442/2008) e Espaços Naturais, Arquiteturas, Arte rupestre e Deposições na Pré-história Recente da Fachada Ocidental do Centro e Norte Português: das Ações aos Significados - ENARDAS (PTDC/HISARQ/112983/2009), financiado pelo Programa Operacional Temático Factores de Competitividade (COMPETE) e comparticipados pelo Fundo Comunitário Europeu FEDER.

Os autores agradecem à Fundação para a Ciência e a Tecnologia (FCT) as bolsas individuais (SFRH/ BD/65143/2009) e (SFRH/BPD/73245/2010) concedidas a João Fonte e Elin Figueiredo, respetivamente, e o apoio financeiro concedido ao CENIMAT/I3N através do Projecto Estratégico LA25/2013-2014 (PEst-C/CTM/LA0025/2011); a Joe Horst os esclarecimentos gentilmente cedidos sobre as condições de achado; à empresa Metais Jaime Dias, S.A. e ao Dr. Normando Ramos a possibilidade do uso do equipamento de FRX portátil para o estudo preliminar da coleção metálica e à equipa do Museu D. Diogo de Sousa, em Braga, o tratamento e fotografia do conjunto.

\section{BIBLIOGRAFIA}

Alves, L.B. \& ReIS, M. 2011. Memoriais de pedra, símbolos de identidade. Duas novas peças escultóricas de Cervos (Montalegre, Vila Real). In R. Vilaça (coord.): Estelas e Estátuas-menires: da Pré à Proto-História, Sabugal: 187-216.

BARREIROS, B. 1920. Materiais para a arqueologia do concelho de Montalegre. O Arqueológo Português 24, 1 série: $58-87$.

BetTenCourT A.M.S. 1998. O conceito de Bronze Atlântico na Península Ibérica. In S.O. Jorge (ed.) Actas do Colóquio Existe uma Idade do Bronze Atlântico? (Lisboa 1995). Trabalhos de Arqueologia - 10. Lisboa: IPA, 18-39.

BettenCOURT A.M.S. 1999. A paisagem e o homem na bacia do Cávado durante o II e o I milénios AC. 5 vols. Braga: Universidade do Minho (Dissertação de Doutoramento policopiada).

BetTenCourT A.M.S. 2001. Aspectos da metalurgia do bronze no Entre-Douro-e-Minho, no quadro da Proto-história do Noroeste Peninsular. Arqueologia 26: $13-40$.

BETTENCOURT A.M.S. 2006. A transformação da paisagem e a

${ }^{8}$ Coloca-se aqui o problema da cronologia da placa de cobre que tanto poderá ser de um período distinto como ter sido fabricada deliberadamente em cobre, durante o Bronze Final, atendendo às propriedades particulares deste metal quando comparadas com uma liga de bronze, ou seja, a sua maior dutilidade, característica que poderia ter sido importante para a obtenção da finura pretendida para a placa.

${ }^{9}$ Contabilizámos o punhal parcialmente fraturado na lingueta e os dois alfinetes. 
construção de lugares de memória durante a Préhistória Recente do Norte de Portugal: o vale do Assureira. Actas das XVI Jornadas sobre a Função Social do Museu. Ecomuseu do Barroso. Identidade e Desenvolvimento. Montalegre: Câmara Municipal e Ecomuseu do Barroso, 109-123.

Bettencourt A.M.S. 2013. A Pré-História do Noroeste Português / The Prehistory of the Northwestern Portugal, Territórios da Pré-História em Portugal, vol. 2, Braga/Tomar: CEIPHAR/CITCEM

Bottaini, C. E. 2012. Depósitos metálicos do Bronze Final (sécs. XIII-VII A.C.) do Centro e Norte de Portugal. Aspectos sociais e arqueometalúrgicos. Coimbra: Universidade de Coimbra (Dissertação de doutoramento - policopiada).

Carvalho, C., Lemos, F.S. \& Meireles, C. 2006. Conjunto Mineiro Romano em Montalegre. Actas das XVI Jornadas sobre a Função Social do Museu. Ecomuseu do Barroso. Identidade e Desenvolvimento. Montalegre: Câmara Municipal e Ecomuseu do Barroso, 147-156.

Coffyn, A. 1985. Le Bronze Final Atlantique dans la Péninsule Ibérique. Bordeaux: Centre Pierre Paris.

CostA, J.G. 1963. Achado arqueológico encontrado em Solveira, concelho de Montalegre em Abril de 1961. Lucerna 3: 119-125.

FigueIREDO, E. 2010. A Study on Metallurgy and Corrosion of Ancient Copper-based Artefacts from the Portuguese Territory. Lisboa: Universidade Nova de Lisboa, Faculdade de Ciências e Tecnologia (Dissertação de doutoramento - policopiada).

Figueiredo, E.; ARAÚJO, M.F.; SILVA, R.J.C.; BRAZ FERNANDES, F.M.; SENNA-MarTineZ, J.C.; INÊS VAZ, J.L. 2006. Metallographic studies of copper based scraps from the Late Bronze Age Santa Luzia archaeological site (Viseu, Portugal). In R. Fort, M Alvarez de Buergo, M. Gomez-Heras, C. VazquezCalvo (eds.) Heritage, Weathering and Conservation. Vol. I. London: Taylor and Francis, 143-149.

Figueiredo, E.; VALÉrio, P.; ARAúJO, M.F.; SENNAMARTINEZ, J.C. 2007a. Micro-EDXRF surface analyses of a bronze spear head: Lead content in metal and corrosion layers. Nuclear Instruments \& Methods in Physics Research A 580: 725-727.

FigueIREdO, E.; ARAúJO, M.F.; SILVA, R.J.C., SENNAMARTINEZ, J.C. 2007b. Corrosion of bronze alloy with some lead content: implications in the archaeometallurgical study of Late Bronze Age metal artefacts from "Fraga dos Corvos" (North Portugal). METAL07 (ICOM-CC) Proceedings, Amsterdam, 2007. Vol. I, 61-66.

Figueiredo, E.; Melo, A., AraúJo, M.F. 2007c. Artefactos metálicos do Castro de Pragança: um estudo preliminar de algumas ligas de cobre por Espectrometria de Fluorescência de Raios X. O Arqueólogo Português 4 (25): 195-215.

FIGUEIREDO, E.; SILVA, R.J.C.; SENNA-MARTINEZ, J.C.; ARAÚJO, M.F.; FERNANDES, F.M.B.; VAZ, J.L.I. 2010a. Smelting and recycling evidences from the Late Bronze Age habitat site of Baiões (Viseu, Portugal). Journal of Archaeological Science 37: 1623-1634.

FIgUEIREDO, E.; SILVA, R.J.C.; ARAÚJO, M.F.; SENNAMARTINEZ, J.C. 2010b. Identification of ancient gilding technology and Late Bronze Age metallurgy by EDXRF, Micro-EDXRF, SEM-EDS and metallographic techniques. Microchimica Acta 168: 283291.
Figueiredo, E.; VAlÉrio, P.; AraúJo, M.F; Silva, R.J.C.; MONGE SOARES, A. 2011a. Inclusions and metal composition of ancient copper-based artefacts: a diachronic view by Micro-EDXRF and SEM-EDS, $X$ -Ray Spectrometry 40: 325-332.

Figueiredo, E.; AraúJo, M. F. Silva, R.J.C.; SENNASARTINEZ, J.C.; VAZ, J.L.I. 2011b. Characterisation of Late Bronze Age large size shield nails by EDXRF, micro-EDXRF and X-ray digital radiography, Applied Radiation and Isotopes 69: 1025-1211.

Figueiredo, E.; ARaúJo, M.F.; Silva, R.J.C.; VilaÇA, R. 2013. Characterisation of a Proto-historic bronze collection by Micro-EDXRF. Nuclear Instruments \& Methods in Physics Research B 296: 26-31.

GutiérReZ NeIRA, P.C.; ZuCChIATtI, A.; MONTERO-RuIZ, I.; VilaÇA, R.; BotTanini, C.; Gener, M.; ClimentFonT A. 2011. Late Bronze Age hoard studied by PIXE. Nucl. Instrum. Methods Phys. Res. Sect. B 269: 3082-3086.

HARDING, A. 2003. Sociedades Europeas en la Edad del Bronce. Barcelona: Ariel Historia.

Monteagudo L. 1977. Die Beile auf der Iberischen Halbinsel, Munchen: Prähistorische Bronzefunde IX, Vol. Band 6.

Needham S.; Bowman S. 2005, Flesh-Hooks, Technological Complexity and the Atlantic bronze Age Feasting Complex, European Journal of Archaeology 8 (2): 93 -136 .

Nunes, J.C.; GiL, F.B.; SenNA-Martínez, J.; Guerra, F. 1989. Artefacto metálico recolhido na casa da Orca da Cunha Baixa, concelho de Mangualde. In Actas do I Colóquio Arqueológico de Viseu. Viseu: Governo Civil, 61-63.

SANTOS JÚNIOR J.R.. 1968, Quatro lanças de bronze de Lama Chã (Montalegre), Trabalhos de Antrologia e Etnologia 20 (3-4): 339-347.

TeIXeIrA, C.; Assunção, C.T. 1970. Carta geológica de Portugal na escala 1/50 0000. Notícia explicativa da folha 2-D. Vilar de Perdizes: Lisboa: Serviços Geológicos de Portugal.

Valério, P., Araújo, M.F., Senna-Martinez, J.C., Vaz, J.L.I. 2006. Caracterização química de produções metalúrgicas do Castro da Senhora da Guia de Baiões. O Arqueólogo Português 24: 289-319.

VALÉRIO, P., ARAÚJO, M.F., CANHA, A. 2007. EDXRF and micro-EDXRF studies of Late Bronze Age metallurgical productions from Canedotes (Portugal). Nuclear Instruments and Methods in Physics Research B 263: 477-482.

VILAÇA, R. 1997. Metalurgia do Bronze Final da Beira Interior: revisão dos dados à luz de novos resultados. Estudos Pré-Históricos 5: 123-154.

VILAÇA, R. 2006. Depósitos de Bronze do Território Português. Um debate em aberto, O Arqueólogo Português, Série IV, 24:9-150.

VILAÇA, R. 2008-2009. Sobre tranchets do Bronze Final do Ocidente Peninsular, Portugália, Nova Série, XXIXXXX: 61-84

Vilaça, R.; Almeida, S.; Bottaini, C.; Marques, J. N.; MonTERo-RUIZ, I. 2011. Metalurgia do Castro do Cabeço da Argemela (Fundão): formas, conteúdos, produções e contextos. In C.B. MARTINS, A.M.S. BetTENCOURT, J.I.F.P. MARTINS \& J. CARVALHO (eds). Povoamento e Exploração de Recursos Mineiros na Europa Atlântica Ocidental. Braga: CITCEM, APEQ, 427-451. 